\title{
O TRANSPORTE AQUAVIÁRIO COMO ALTERNATIVA DE MOBILIDADE URBANA NA REGIÃO METROPOLITANA DE BELÉM-PA.
}

\author{
River transportation as an alternative for urban mobility \\ in the metropolitan region of Belém/ PA.
}

\author{
Arthur Aviz Palma e Silva ${ }^{1}$, Rita de Cassia Monteiro Moraes ${ }^{2}$ Christiane Lima Barbosa ${ }^{3}$
}

Recebido em 30 de setembro de 2018; aceito em 07 de abril de 2019; disponivel on-line em 18 de setembro de 2019.

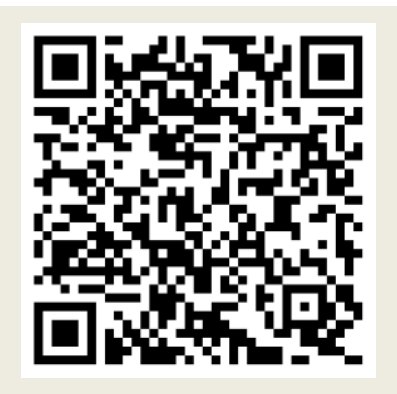

PALAVRAS CHAVE:

Transporte aquaviário;

Mobilidade urbana;

Transporte público;

Região amazônica;

Tráfego.

\section{KEYWORDS:}

River transportation;

Urban Mobility;

Public transportation;

Amazon region;

Traffic.

RESUMO: A implantação de grandes empreendimentos em regiões específicas dos grandes centros urbanos, promove o deslocamento da população de baixa renda para zonas periféricas, devido ao aumento dos preços dos imóveis no local. Essa mudança ocorre muitas vezes sem qualquer tipo de planejamento de mobilidade e infraestrutura, o que aumenta o índice de acidentes e lentidão de tráfego. Algumas cidades, como é o caso de Belém/ PA, estão localizadas na região amazônica, rodeada por rios que podem ser utilizados como alternativa de mobilidade para a redução destas questões. Este trabalho, tem como objetivo verificar a percepção qualitativa do usuário sobre o meio de transporte rodoviário que interliga duas regiões da cidade (uma no centro, e uma na região periférica), bem como avaliar a o interesse dos passageiros por um meio de transporte aquaviário auxiliando na mobilidade urbana. Foram aplicados questionários para obtenção de opinião popular com questionamentos acerca de indicadores de qualidade obtidos em referencial bibliográfico, e também a respeito da implantação de um modal alternativo. Os resultados demonstram grande precariedade na qualidade do serviço prestado ao usuário do modal rodoviário que interliga zonas periféricas e zonas centrais da cidade, bem como a grande receptividade da população residente da zona periférica a respeito da implantação do transporte aquaviário, realizando o mesmo trajeto que hoje só é feito pelas vias terrestres. Os diagnósticos obtidos, podem embasar futuras políticas públicas para desenvolvimento da mobilidade na cidade.

ABSTRACT: The implementation of large enterprises in specific regions on urban centers, leads to the displacement of low-income population to peripheral zones, due to the increase of prices of properties on that place. This fact often occurs without any kind of mobility and infrastructure planning, which increases the rate of accidents and slow traffic. Some cities, such as Belém / PA, are located inside the Amazon region, surrounded by rivers that can be used as mobility alternatives to reduce these issues. This paper, therefore, aims to verify the qualitative perception of the population about the road transportation that interconnects two regions of the city (one in the center, and one in the peripheral region), as well as evaluate the interest of the passengers about river transportation aiding urban mobility. Questionnaires were used to obtain popular opinion about quality indicators, taken from bibliographic references, and also regarding to the implementation of an alternative modal. The results show a great precariousness in the quality of the service provided to the user of the road modal that interconnects peripheral and central zones of the city, as well as the great receptivity of the resident population of the peripheral zone in terms of the implantation of the waterway transport, carrying out the same route that today it is only made by land. The diagnoses obtained, can support future public policies for the development of mobility in the city.

* Contato com os autores:

${ }^{1}$ e-mail: eng.aviz@gmail.com ( A. A. Palma e Silva )

Engenheiro Civil (UFPA), pesquisador do laboratório de engenharia civil da Universidade Federal do Pará.

2e-mail: moraes.rita@hotmail.com (R. C. M. Moraes )

Doutoranda em Engenharia de Recursos Naturais da Amazônia (UFPA), Mestrado em Engenharia Civil (UFPA), docente do curso de Engenharia Civil da Universidade Federal do Pará na área de Engenharia de transportes.

${ }^{3}$ e-mail: cllima@ufpa.br (C. L. Barbosa)

Doutorado e Mestrado em Engenharia Civil (UNICAMP), docente do curso de Engenharia Civil da Universidade Federal do Pará na área de Engenharia de transportes. 


\section{INTRODUÇÃO}

A modificação do aspecto demográfico da população nos grandes centros urbanos do Brasil tem se mostrado um verdadeiro desafio para a administração dos estados e municípios, principalmente quando se trata de mobilidade urbana. Neste contexto, os ônibus são um importante meio de transporte coletivo, que são capazes de interligar diversas áreas das grandes metrópoles brasileiras. Este modal está conectado ao crescimento industrial, comercial e socioeconômico de uma região, e é capaz de minimizar impactos ambientais, congestionamentos e acidentes rodoviários (Kato, Bordalo e Camelo, 2016). É essencial no contexto da infraestrutura urbana, pois possibilita o deslocamento da população de diversas faixas de renda. Os governos, tratando-se de mobilidade urbana, tem como foco principal em suas políticas públicas a transferência de passageiros dos veículos particulares, para os veículos coletivos, como os ônibus, através da atratividade com veículos de ponta e máximo conforto (Vasconcellos, 1996). Esta ferramenta é muito importante para reduzir-se a quantidade de automóveis particulares presentes nas grandes cidades.

$\mathrm{Na}$ cidade de Belém - PA, foco do presente estudo, $\mathrm{O}$ descompasso entre $\mathrm{O}$ planejamento da mobilidade e a política habitacional, gerou inchamento acelerado, devido a mudança do desenho urbanístico com a implantação dos diversos conjuntos habitacionais construídos, transformando o que antes era área rural, em área urbana (Lima, Silva e Cruz, 2014). A população, em sua maioria de baixa renda, se expandiu para os bairros e distritos próximos, como é o caso do distrito administrativo de Icoaraci (DAICO). Isto ocorre principalmente pelo encarecimento dos imóveis da zona central da cidade, fato recorrente em diversas outras capitais brasileiras (Smith e Raemaekers, 1998). Em paralelo a isso, a falta do planejamento urbano mediante a este crescimento populacional fez com que grandes empreendimentos se concentrassem apenas nos bairros centrais de Belém, a exemplo a própria Universidade Federal do Pará (Silva e Dias, 2011).

Concomitantemente, a região metropolitana de Belém detém, ao longo de sua orla, os rios Pará e Guamá, 19 bacias hidrográficas que compõem sua parte continental e mais de 30 que compõem sua parte insular (Brasil, 1991). Este potencial hídrico não é aproveitado para o benefício da mobilidade urbana da população, principalmente em prol dos distritos que compõem a região.

Assim, para um melhor entendimento da influência do processo de desenvolvimento urbano na qualidade do transporte oferecido para as zonas periféricas da cidade, são necessários dados qualitativos sobre o transporte urbano que interliga pontos em zonas de distrito administrativo ao longo da região metropolitana de Belém. Contudo, também se fazem necessários dados acerca da aceitação da população ao transporte aquaviário, como forma de otimização dos meios de transporte para este trajeto, aproveitando assim o potencial hidroviário.

\section{OBJETIVO}

O objetivo desta pesquisa consiste em avaliar, através de dados de percepção qualitativa fornecidos pelos próprios usuários da linha de transporte rodoviário, a qualidade do serviço de transporte urbano oferecido à população residente nas zonas periféricas da região metropolitana de Belém, tendo como alvo do estudo de caso, a linha de ônibus 305: UFPA Icoaraci. Buscou-se ainda observar a aceitação por parte dos passageiros da linha rodoviária, a introdução de um modal aquaviário conectando a região de Icoaraci (DAICO) à Universidade Federal do Pará, interligando dessa forma os mesmos pontos da linha rodoviária, porém aproveitando o potencial hidrográfico da Região. 


\section{REVISÃO BIBLIOGRÁFICA}

O processo de urbanização o qual passou a região metropolitana de Belém, tornou-se uma fonte de preocupação em termos de mobilidade urbana. Segundo censo demográfico do Instituto Brasileiro de Geografia e Estatística (2016) sobre a frota rodoviária, existiam na cidade 223.656 automóveis particulares e apenas 3.818 veículos de transporte coletivos, demonstrando extrema discrepância entre a utilização dos meios de transporte coletivo pela população. A região metropolitana de Belém cresce conforme ocorre o processo de expansão de sua zona urbana, que sofre alteração por conta da forma como ocorre o avanço econômico da região amazônica (Tobias, Neto e Neves, 2008). Os conjuntos habitacionais presentes na cidade foram iniciados em meados dos anos 70 e 80 , com a transformação de terras rurais em terras urbanas, devido ocupação informal de terras públicas e privadas, e atualmente observa-se a atração de grandes pontos comerciais nesta região ao longo da Rodovia Augusto Montenegro, como shopping centers, universidades, e supermercados, norteados pela perspectiva de crescimento de poder aquisitivo da população residente naquela região. Ao longo da rodovia existem bairros desconectados urbanisticamente devido a falta de uma rede viária continua (Lima, Silva e Cruz, 2014) prejudicada ainda mais por um padrão habitacional fragmentado presente na região. Esse crescimento da região metropolitana, associado a falta de planejamento urbano, gerou situações extremamente danosas à qualidade de vida da população em questão, caracterizando-se pelas enchentes, tráfego intenso de veículos e sobrecarga da malha viária (Silva e Dias, 2011).

A zona periférica da região metropolitana de Belém é dividida em Macrorregiões, denominadas distritos administrativos, os quais facilitam a administração pública da cidade. O DAICO (Distrito Administrativo de Icoaraci) tem destaque por se tratar de uma região de cunho industrial. A Figura 1 representa a distribuição dos distritos administrativos da região metropolitana de BelémPA.

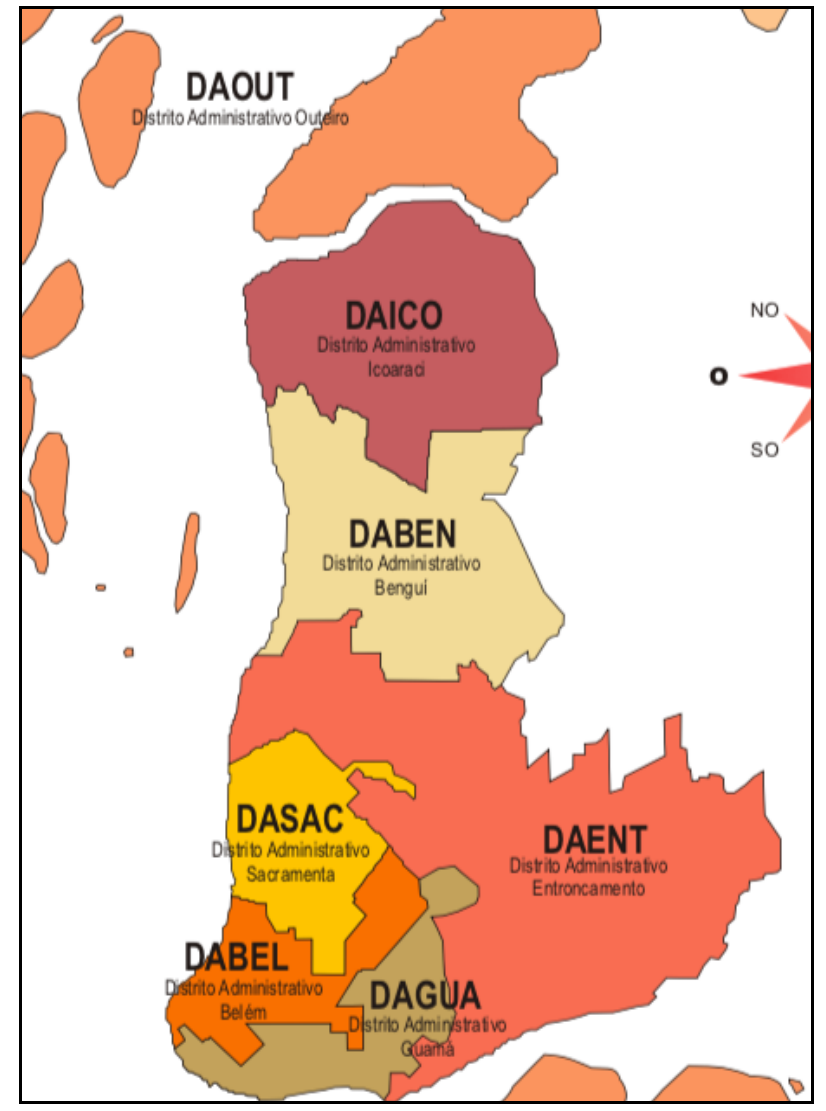

FIGURA 1: Mapa dos distritos administrativos da região metropolitana de Belém - PA.

FONTE: Adaptado de Secretaria Municipal de Coordenação Geral do Planejamento e Gestão de Belém (Belém, 1994).

Este distrito se localiza na outra ponta do mapa da cidade, quando relacionado ao centro comercial de Belém, e mesmo assim possui grande número de habitantes, tendo passado por muitas tentativas de emancipação nos anos pretéritos. É composto pelos bairros: Maracacuera, Cruzeiro, Ponta Grossa, Campina, Parque Guajará, Águas Negras, Agulha e Paracuri. Alguns desses bairros contam com pequenos portos de transporte fluvial (Tobias, 2007), como é o caso do Bairro do Cruzeiro, que pode ser visualizado na Figura 2. Este terminal hidroviário é amplamente utilizado para transporte de passageiros e produtos às ilhas ao redor da Região Metropolitana de Belém. 


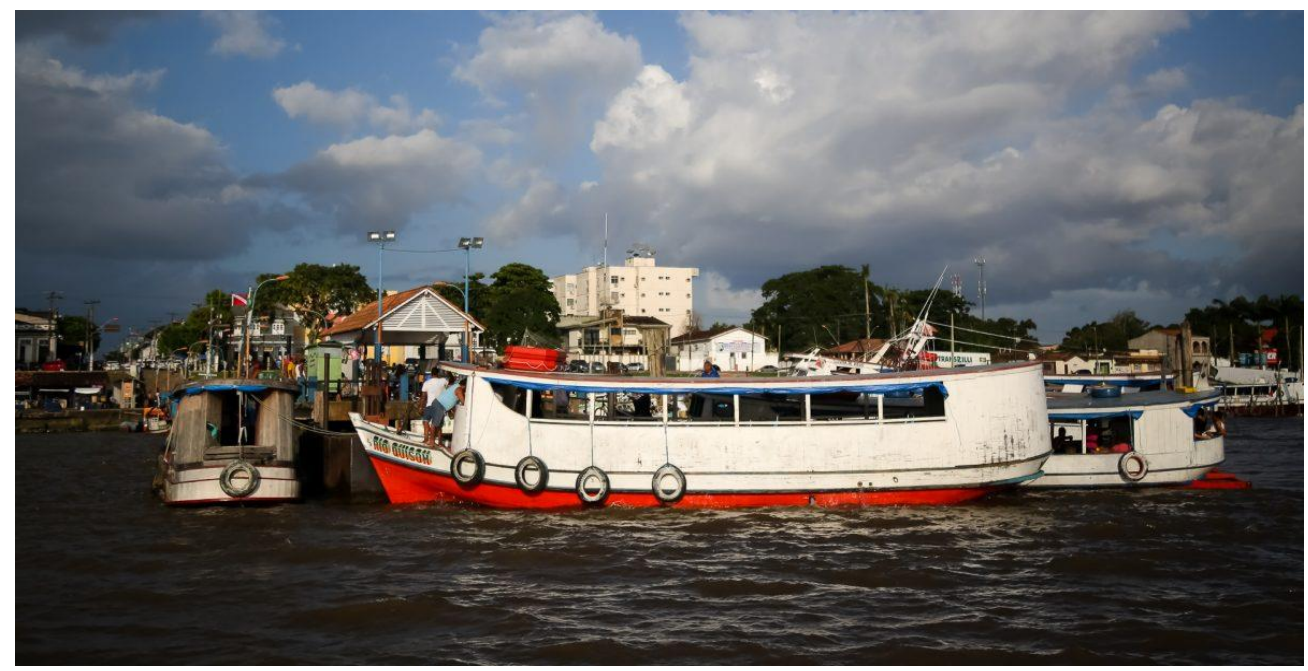

FIGURA 2: Terminal hidroviário de Icoarací.

FONTE: Uchôa Silva-Agência Belém (2017).

No Distrito Administrativo do Guamá (DAGUA), no lado oposto ao DAICO, se encontra o maior centro de ensino da região norte do país, a Universidade Federal do Pará, a qual hoje conta com mais de 60.000 alunos em seus cursos de graduação, pós-graduação e quadro técnico. Para interligar estes dois pontos, a única linha de ônibus que oferece transporte urbano público direto, é a linha 305 UFPA - Icoaraci, a qual percorre a Rodovia Augusto Montenegro, captando não só os passageiros do DAICO, mas também sendo utilizada por outros distritos que têm como destino último a Universidade (Belém, 2009). Esta situação pode gerar desconforto para os passageiros, devido ao descumprimento da lotação do veículo, assim como deficiência no tempo de chegada ao seu destino final (Rodrigues, 2006). Como consequência, ocorre também o surgimento de meios de transporte alternativos, como é o caso do moto taxi, que de acordo com o IBGE (2005), já está presente em $72 \%$ dos municípios do Norte.

Ao redor do Brasil e do mundo, observam-se casos bem-sucedidos de substituição ou integração de modais de transporte urbano e aquaviário, solucionando diversos problemas causados pelo inchamento das cidades e mal planejamento do sistema de transporte público urbano. A travessia Rio - Niterói, apesar de contar com a construção de uma ponte, ainda hoje possui várias embarcações que realizam o trajeto, entre barcaças antigas e novas, e ainda catamarãs. Essas embarcações realizam todos os dias o transporte de cerca de 80 mil passageiros, e o tempo de travessia de um ponto a outro do trajeto varia entre 20 a 40 minutos. A substituição do modal urbano pelo modal aquaviário acaba se tornando agradável ao passageiro, que realiza sua viagem mais rápido e tem o conforto da embarcação aparelhada para tal fim (Leite, 2014). Porém antes da propor ao usuário uma substituição do seu método de deslocamento, principalmente por meios públicos, é necessário que se analise a percepção do próprio passageiro acerca da qualidade de seu modal, e esta avaliação pode ser gerada por meio dos indicadores de produtividade e qualidade (Tironi, 1991).

\section{METODOLOGIA}

O campo de estudo desta pesquisa foi a cidade de Belém do Pará, que tem como foco para mobilidade urbana o transporte rodoviário, sem significativa integração. 0 objeto de pesquisa utilizado, foi uma das linhas de ônibus mais importantes da cidade, a linha 305 UFPA Icoaraci. Os dados foram coletados baseando-se nos indicadores propostos por Ferras e Torres (2004), adaptando-se alguns deles para que houvesse compatibilidade com o público do de instalação de meio hidroviário para trajeto 
questionamentos a respeito de cada um dos tópicos de pesquisa com as seguintes notas: Excelente, Bom, Regular, Ruim, Muito Ruim.

Os itens qualitativos do questionário confeccionado seguiram a ordem abaixo:

(1) Acessibilidade: Distância da residência até o ponto de subida no ônibus, e de descida do veículo o destino final;

(2) Frequência de atendimento: Tempo de espera na parada pela vinda do ônibus;

(3) Lotação: O limite de lotação do veículo é respeitado;

(4) Tempo de Viagem: Tempo de chegada até o destino final do passageiro;

(5) Veículos: Estado de conservação e conforto dos ônibus da Linha;

(6) Comportamento de operadores: Avaliação do comportamento dos motoristas e cobradores em relação ao respeito e eficiência no atendimento ao passageiro;

(7) Tarifa: Preço da tarifa urbana de transporte da linha;

(8) Segurança: Assaltos e acidentes ocorridos dentro do veículo e nas paradas em questão;

(9) Opinião da população sobre a criação de uma linha de transporte fluvial universitária, interligando o porto localizado na orla do Cruzeiro em Icoaraci a orla da Universidade Federal do Pará. Características do Barco: Catamarã ou Barcaça. Tempo de viagem: 20 a 30 minutos. Tarifa: $\mathrm{R} \$$ 5,00. Wi-fi, salão de jogos, ar condicionado e lanchonete.

O item 9, acerca da aceitação da implantação do transporte aquaviário para interligar diretamente os dois pontos (UFPA e o distrito de Icoaraci), teve duas opções de resposta: Sim e Não. Os preços, tempo de viagem, e proposta de tarifa foram baseados no trabalho de Leite (2014), bem como em experiência pretérita similar na cidade de Belém. Se a resposta fosse negativa, os entrevistados deveriam discorrer sobre a razão de não utilizarem o meio de transporte proposto. As opiniões populares no último ponto do questionário foram introduzidas para que fossem identificados os entrevistados que utilizavam a linha de transporte 305 UFPA Icoaraci exclusivamente para ir de uma ponta a outra do trajeto, ou seja, para ir da Universidade Federal do Pará ao DAICO, e vice-versa, e os que apenas utilizam a linha como meio de transporte para a Universidade, mas que não residiam no distrito.

Separar os dois públicos foi de extrema importância para este trabalho, tendo em vista que um de seus objetivos era compreender a aceitação do público ao transporte hidroviário, porém somente $\mathrm{o}$ passageiro que reside em Icoaraci e utiliza da linha do início ao fim, seria um potencial utilizador da proposta hidroviária para o trajeto. A Figura 3 representa as trajetórias dos modais rodoviário e hidroviário do DAICO até a Universidade Federal do Pará.

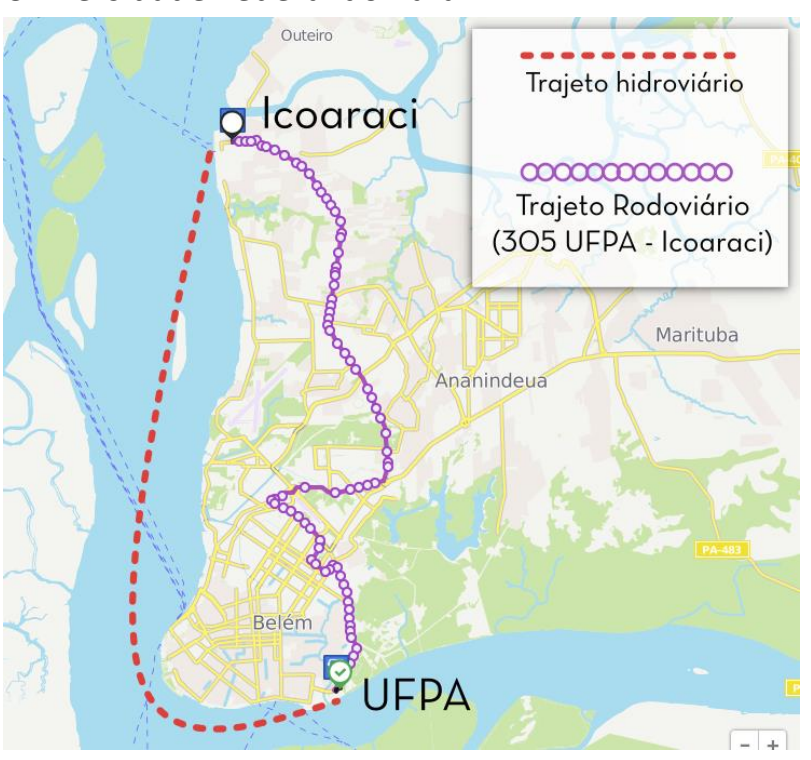

FIGURA 3: Trajetos hidroviário e rodoviário de interligação entre o DAICO e a Universidade Federal do Pará.

FONTE: Adaptado do aplicativo MOOVIT (2018). 
$O$ estudo foi delimitado a pessoas que obrigatoriamente utilizassem a linha 305 UFPA Icoaraci e que realizassem alguma atividade na Universidade, sendo estes, alunos ou técnicos. 0 questionário foi aplicado de forma virtual, através de divulgação nas principais mídias sociais. 0 intervalo de aplicação foi de 30 dias e o número de entrevistados foi de 178 usuários, sendo estes 176 estudantes e 2 técnicos.

\section{RESULTADOS}

\subsection{ACESSIBILIDADE}

$\mathrm{O}$ item acessibilidade, relacionou o grau de satisfação dos usuários da linha 305 UFPA Icoaraci com a distância que deviam percorrer dos seus pontos de subida e descida do veículo, até suas residências ou locais de trabalho e estudo. A Figura 4 permite inferir que 30,9\% dos que responderam o questionário, consideram "ruim" ou "muito ruim" a distância tratada. Este dado permite que se afirme que boa parte dos usuários não são contemplados com pontos de ônibus suficientemente próximos aos locais em que se destinam.

Contudo, $69,1 \%$ classificou o item como "bom", "regular" ou "muito bom", o que pode ser considerado um resultado positivo para esse índice. Porém, dentre as respostas, há de se considerar ainda que parte dos usuários da linha tem como destinação final a Universidade Federal do Pará, que conta com um terminal rodoviário praticamente dentro de seu território. Este dado torna-se importante quando se considera que a coleta de dados foi totalmente feita com público universitário, sejam eles técnicos ou estudantes. Portanto, as respostas negativas para este item, se relacionam intimamente com distâncias entre os pontos de subida no ônibus e as residências dos passageiros, reforçando a deficiência de planejamento urbano no DAICO por conta da ausência de políticas públicas que acompanhassem 0 surgimento dos grandes empreendimentos e lançamentos imobiliários ao longo da região periférica da cidade. (Guimarães 2012).

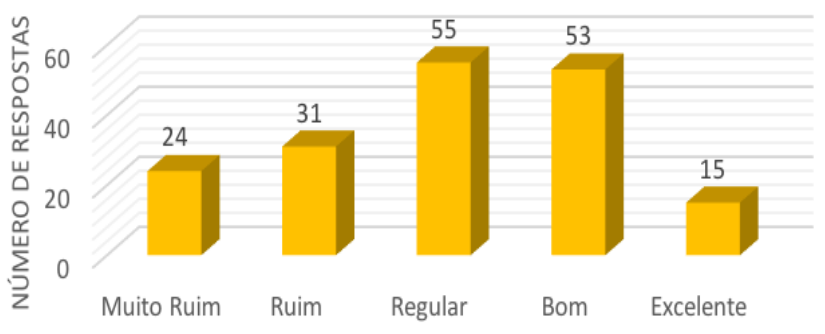

FIGURA 4: Número de respostas para o índice de acessibilidade.

FONTE: Acervo pessoal.

\subsection{FREQUÊNCIA DE ATENDIMENTO}

$O$ item frequência de atendimento diz respeito ao tempo de espera na parada pela vinda do ônibus. As respostas ao questionário permitem que se afirme que a quantidade de unidades da mesma linha de ônibus que opera para o transporte de passageiros neste trajeto não é suficiente para atender a demanda. A deficiência na frequência de atendimento de uma linha de ônibus pode ser altamente prejudicial ao passageiro, e uma das principais consequências observadas da ausência de regularidade no atendimento das linhas pode ser o aumento do índice de desrespeito à lotação pelo veículo (Kato, Bordalo e Camelo, 2016). A Figura 5, demonstra o auto índice de insatisfação dos usuários da linha em questão, onde $61,2 \%$ classificaram este item como "muito ruim" e $23,7 \%$ como "ruim", totalizando $84,9 \%$ de opiniões negativas acerca da espera das unidades de ônibus nas paradas.

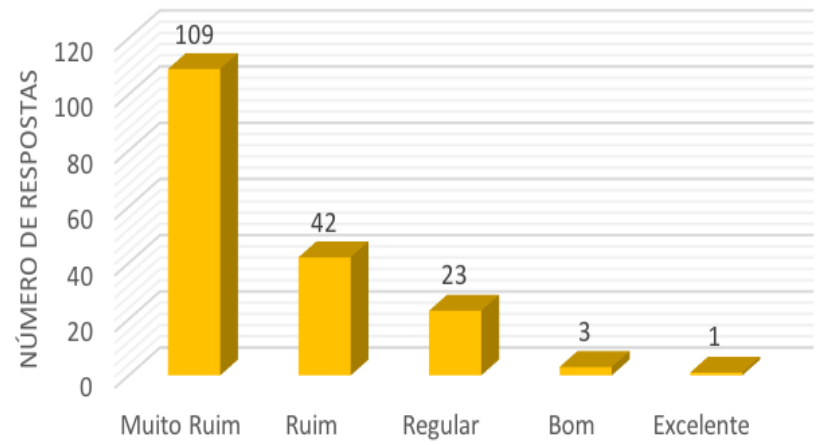

FIGURA 5: Número de respostas para frequência de atendimento.

FONTE: Acervo pessoal.

Como consequência, ocorre ainda o surgimento de meios de transporte alternativos, moto taxis e vãs, que estão presentes em larga escala nos distritos administrativos e muitas vezes operam de forma irregular. 


\subsection{LOTAÇÃO}

A lotação é a capacidade máxima de transporte de passageiros, sentados e em pé. Este número pode variar de acordo com o modelo do veículo e de acordo com leis do município ou do estado em questão, que reduzem a capacidade de passageiros por segurança, ou mesmo para o maior conforto do usuário. Como era esperado, o item "frequência de atendimento" tem direta relação com o item "lotação". Obteve-se cerca de $80 \%$ de reprovação acerca da frequência de ônibus na parada, e a Figura 6 demonstra que este resultado acompanhou o índice de lotação, variando muito pouco o resultado de percepção qualitativa.

Em termos de lotação, o número de unidades do ônibus em questão não é o único ponto a ser discutido. A falta de regularidade dos horários de circulação dos veículos agrava a deficiência de frequência de atendimento, que por sua vez, impacta a percepção do usuário sobre a lotação do meio de transporte. Ocorre que o transporte realizado na cidade de Belém é feito por diversas empresas, donas de grandes frotas de ônibus, que não operam interligadas umas com as outras, gerando assim falta de organização nos horários de atendimento.

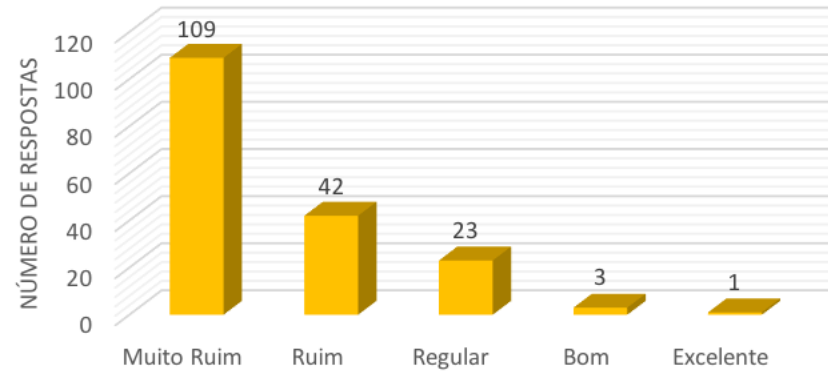

FIGURA 6: Número de respostas para o índice de lotação.

FONTE: Acervo pessoal.

\subsection{TEMPO DE VIAGEM}

Este item diz respeito ao tempo de viagem que o passageiro leva até chegar ao seu destino final, que neste estudo pode ser representado por qualquer ponto que esteja no trajeto da linha 305 UFPA - Icoaraci. Vale ressaltar que foi deixado claro durante a aplicação do questionário que este item se relacionava apenas ao tempo de viagem dentro do veículo, a partir do momento da subida do usuário que esperava no ponto. $\mathrm{O}$ grau de satisfação dos usuários acerca do tempo de viagem, pode ser visualizado na Figura 7, onde $39 \%$ dos usuários classificaram o item como "muito ruim" e $24,3 \%$ como "ruim", totalizando mais de $60 \%$ de reprovação por conta dos entrevistados.

O tempo de viagem depende de diversos fatores ao longo do percurso. Dois destes fatores são decisivos para a avaliação deste índice, são eles: a qualidade do pavimento da via e o fluxo de veículos circulando simultaneamente. A cidade de Belém se localiza na região tropical amazônica, apresentando índice de precipitação média entre 2.300 e $3.500 \mathrm{~mm}$.ano-1, e chuvas fortes entre os meses de novembro e março (Fisch, Marengo e Nobre, 1998). Este índice pluviométrico contribui para a deterioração dos pavimentos, bem como a diminuição da fluidez de transito nas cidades, produzindo regiões de lentidão de transito $\mathrm{e}$ também acidentes. Esses fatores geram consequências diretas na percepção qualitativa do usuário do transporte público a respeito do tempo de viagem, impactando as respostas de forma negativa.

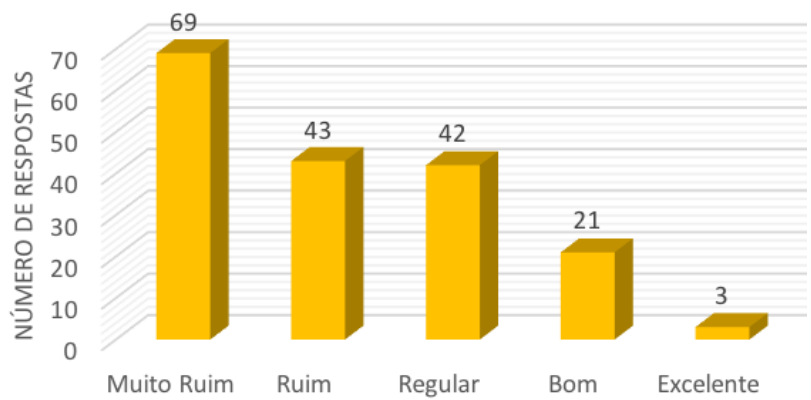

FIGURA 7: Número de respostas para tempo de viagem. FONTE: Acervo pessoal.

\subsection{VEÍCULOS}

Para análise dos veículos utilizados pelas linhas de transporte rodoviário, vários pontos devem ser considerados para uma correta 
respeito das paradas que a linha cobre; Qualidade dos assentos; refrigeração adequada; mecanismos de solicitação de parada; ergometria nos corredores; barras de suporte de locomoção; quantidade e largura das portas e manutenção.

Acerca do estado de conservação dos veículos da linha 305: ICOARACI - UFPA, é nítida a insatisfação dos usuários. Neste trabalho, 57,7\% dos usuários classificaram 0 estado de conservação como "ruim" ou "muito ruim, 36,2\% consideraram o estado "regular" e apenas 6,2\% consideraram o estado dos veículos "bom" ou "muito bom". A deficiência na manutenção dos veículos, gera não só mal-estar para o passageiro que o utiliza, mas também tem relação com o item "tempo de viagem", tendo em vista que a falta de assistência regular, provoca problemas mecânicos nos exemplares. Estes problemas agravam a falta fluidez no transito, tendo em vista que muitas vezes os veículos obstruem vias por conta de acidentes ou falhas de componentes. Portanto, pode-se inferir através resultados de percepção qualitativa obtidos que a qualidade dos ônibus desta linha encontra-se precária, sendo necessária a adequação da linha existente para fornecer serviço de qualidade, ou mesmo a aquisição de novos exemplares. Os resultados numéricos do indicador "veículo" podem ser visualizados na Figura 8.

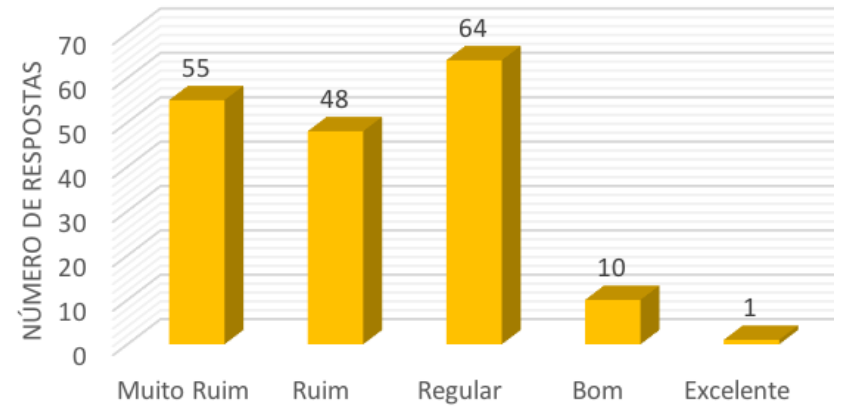

FIGURA 8: Número de respostas para o indicador "veículos".

FONTE: Acervo pessoal.

\subsection{COMPORTAMENTO DOS OPERADORES}

Considera-se neste índice, a qualidade de (motoristas e cobradores) dos ônibus da linha, sendo estes os funcionários das empresas prestadoras de serviço de transporte, que têm contato direto com o usuário. Assim, o fator humano é considerado o único ponto de análise. Considerando os dados demonstrados na Figura 9, notamos que a grande maioria do público analisado considerou $\mathrm{o}$ atendimento como "regular". Diversas variáveis podem influenciar no atendimento humano ao passageiro realizado por conta dos funcionários da linha, como satisfação com salários, carga horária de trabalho, condições dignas no local de ofício, dentre outros. Portanto, pode-se inferir que são necessárias mudanças nas políticas de amparo, treinamento e motivação dos funcionários da empresa de ônibus em questão, para que ocorram melhores avaliações por parte de seus usuários.

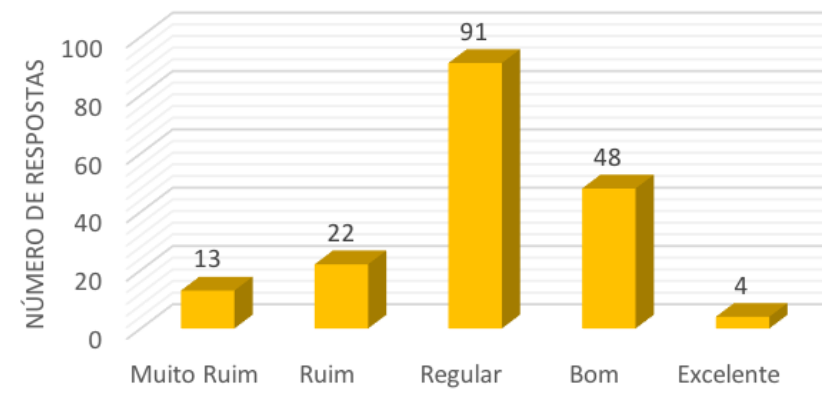

FIGURA 9: Número de respostas para comportamento dos operadores da linha.

FONTE: Acervo Pessoal

\subsection{TARIFA}

Os usuários foram questionados se achavam justo o valor da tarifa da linha de ônibus em relação ao serviço prestado pelas empresas que realizam o trajeto. Conforme a Figura 10, a grande maioria dos usuários considerou que a tarifa cobrada não é compatível com o serviço prestado. Cerca de $90 \%$ das respostas foram de "regular" a "muito ruim", levando em consideração que a grande maioria do público ao qual foi aplicado o questionário é composto por estudantes, que possuem o benefício da meiapassagem. 
fixada em $R \$ 3,30$ e não está estre as mais altas do Brasil. Este valor está, por exemplo, aproximadamente $R \$ 1,40$ mais baixo do que o valor cobrado em Campinas - SP, porém, este item se relaciona não só ao valor cobrado, mas também à qualidade do transporte que é realizado. 0 resultado insatisfatório da percepção popular de tarifa, permite-nos relacionar este indicador com todos os outros abordados neste trabalho, que também apresentaram resultados demasiadamente negativos, com exceção do item "acessibilidade".

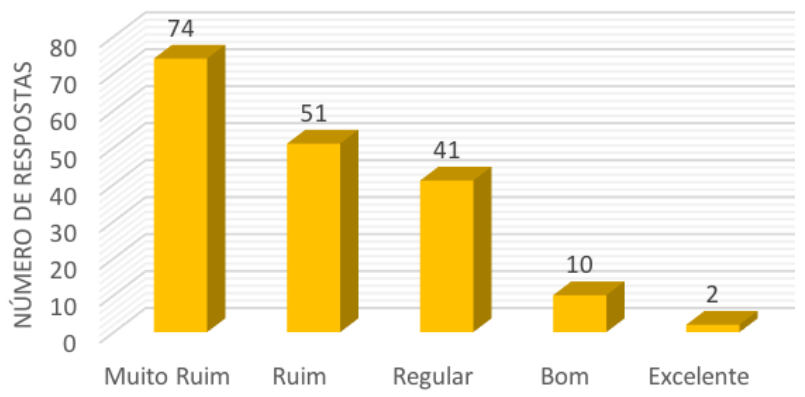

FIGURA 10: Número de respostas para o índice "tarifa". FONTE: Acervo Pessoal.

\subsection{SEGURANÇA}

Considerando-se como de aspecto segurança, a avaliação de todos os acidentes prováveis que poderiam prejudicar a integridade física de todos os fatores integrantes do transporte público. Foram considerados tanto os fatores humanos, como as estruturas físicas do sistema (locais de parada, terminais, estações, veículos, etc.).

Na Figura 11, é possível a verificação da reprovação da população em relação a este modal urbano, onde $87,6 \%$ dos usuários indicou o item como "regular", "ruim" ou "muito ruim". É importante que se considere que neste indicador, que as políticas públicas de segurança são fator decisivo para uma análise negativa da situação dos do veículo.

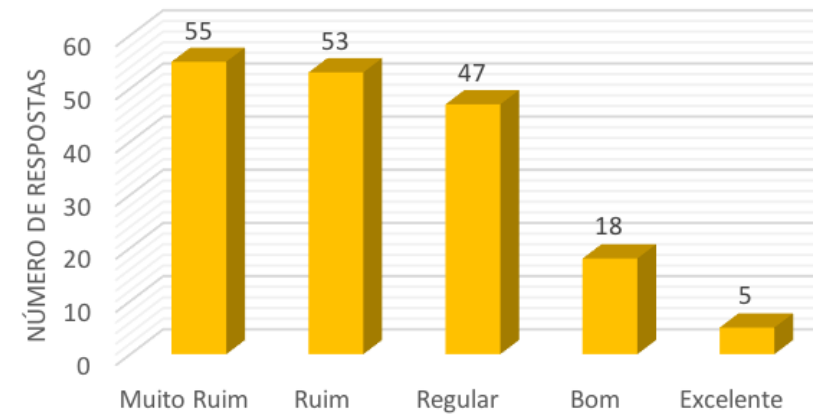

FIGURA 11: Número de resultados para segurança na linha.

FONTE: Acervo pessoal.

\subsection{LINHA DE TRANSPORTE AQUAVIÁRIO}

A análise da criação de um modal aquaviário interligando Icoaraci à UFPA, com base na Figura 12, permite que se afirme que dos 178 usuários entrevistados, 114 aprovam e utilizariam o modal proposto para sua mobilidade. $\mathrm{Na}$ região metropolitana, o uso do modal hidroviário para locomoção ainda é pouco explorado se comparado ao seu uso nas ilhas nos arredores da cidade. Aproximadamente 30\% dos entrevistados reprovou a implantação do meio de transporte, e a justificativa estão dispostas na Figura 13

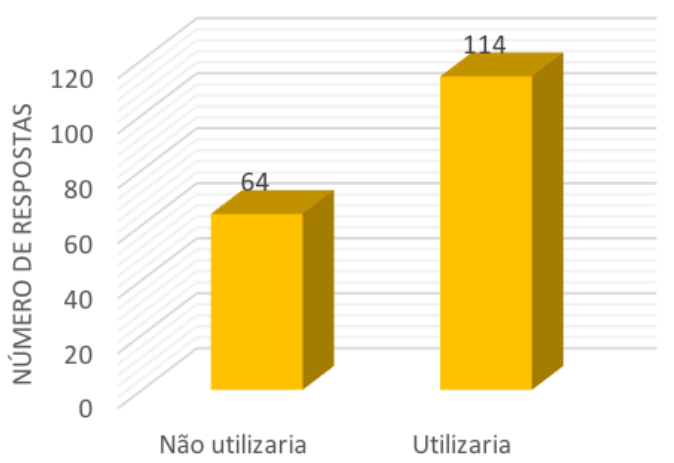

FIGURA 12: Número de usuários que utilizaria ou não a linha de transporte aquaviário que interligaria o bairro do Cruzeiro em Icoaraci à orla da UFPA.

FONTE: Acervo pessoal. 


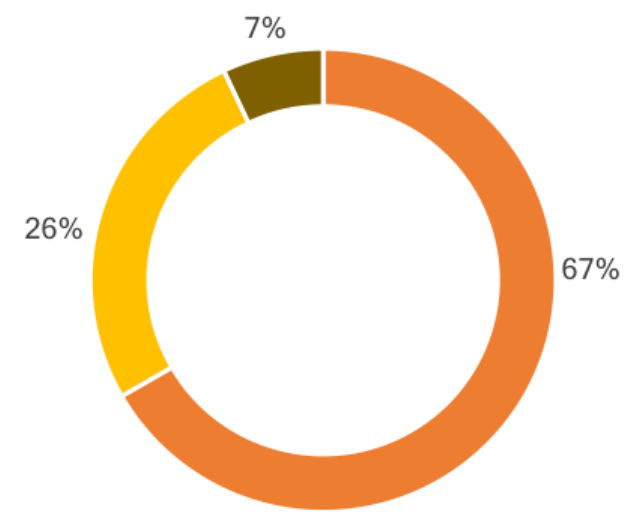

- Não residentes em Icoaraci = Tarifa alta - Outros

FIGURA 13: Principais motivos os quais os passageiros não utilizariam o modal aquaviário.

FONTE: Acervo pessoal.

Entre as justificativas da não utilização do modal aquaviário para o transporte, as mais significativas são o preço da tarifa proposta e a distância ao terminal hidroviário. Dos 64 entrevistados que reprovaram a implantação do meio de transporte hidroviário, $67 \%$ alegou que a localização do porto se situa longe de suas residências, pois não moram em Icoaraci e, portanto, não seriam contemplados com o porto localizado no DAICO. Outros $27 \%$, afirmaram que a tarifa estaria além do que deveria ser cobrado para este tipo de transporte, e $7 \%$ do público alegou outros motivos que os impossibilitariam de utilizar o modal. Vale ressaltar, que a utilização das hidrovias tem como proposta a retirada de passageiros do modal rodoviário para o transporte aquaviário, desafogando o trânsito e melhorando o conforto de quem continuaria utilizando a linha e gerando impacto social e ambiental positivo. Portanto a localização do porto, mesmo que reprovada por uma pequena parte dos usuários, se mostra eficaz para a retirada de pelo menos $60 \%$ do total de todos os entrevistados do modal rodoviário.

A respeito da tarifa, esta pode deve ser ajustada para que ocorra uma melhor aceitação por parte da população para o modal. Esta redução de custo poderia ser feita através da retirada de itens de conforto como salão de jogos e lanchonete da embarcação proposta para o transporte.

\section{CONCLUSÕES}

O transporte urbano rodoviário responsável pela linha que interliga o distrito de Icoaraci a Universidade Federal do Pará 305 UFPA Icoaraci demonstrou baixa satisfação por conta da percepção da população em todos os itens que diziam respeito a sua qualidade, trazendo à tona a necessidade de melhoria deste meio de transporte por conta da empresa responsável e órgãos públicos.

A linha teve como piores itens avaliados, a "frequência de atendimento" e "lotação", os quais apresentam íntima ligação entre si. Os resultados destes indicadores, inferem que existe urgência na reorganização do número de linhas de ônibus, bem como os horários de atendimento contemplados por essas unidades.

O transporte aquaviário apresentou avaliação de percepção qualitativa satisfatória por conta da opinião de possíveis usuários, tendo aceitação de aproximadamente $60 \%$ dos entrevistados no total. A implantação do meio aquaviário poderia redirecionar grande parte dos usuários de transporte urbano rodoviário para as hidrovias pouco aproveitadas na região, proporcionando diversas melhorias em termos de mobilidade urbana e sustentabilidade. $\mathrm{O}$ preço proposto para a travessia do porto de Icoaraci até a Universidade Federal do Pará e vice-versa ainda se mostra oneroso na perspectiva do usuário. Medidas podem ser tomadas para que a proposta se adeque um pouco melhor às condições financeiras de quem utilizaria esta rota arquivaria, como a redução de alguns itens como salão de jogos e lanchonete.

O estudo realizado deve embasar futuras políticas públicas na área da mobilidade urbana na região, proporcionando melhorias para o bemestar da população, e desenvolvimento sustentável atrelado à crescimento tecnológico. 


\section{REFERÊNCIAS BIBLIOGRÁFICAS}

BELÉM. Lei Municipal 7682 de 4 de janeiro de 1994. Dispõe sobre os limites territoriais e distritos administrativos de Belém e Ananindeua. Publicado no Diário Oficial do Municipal em 05/01/1994.

BELÉM. Prefeitura Municipal. Secretaria de Esporte Juventude e Lazer. Rota dos ônibus de Belém. 2009.

BRASIL, PARÁ E AGÊNCIA DE COOPERAÇÃO INTERNACIONAL DO JAPÃO. Plano Diretor de Transportes Urbanos. Região Metropolitana de Belém. Relatório final. Belém: EMTU, 1991.

FISCH, G.; MARENGO, J. A.; NOBRE, C.A. Uma revisão geral sobre o clima da amazônia. ACTA AMAZONICA 28(2), p. $101-126,1998$.

FERRAZ, A. C. P; TORRES, I. G. E. Transporte público urbano. São Paulo, Rima, 2004, 410p.

GUIMARÃES, G. Novas centralidades na malha urbana da Região metropolitana de Belém: Estudo Aplicado ao Espaço da Rodovia Augusto Montenegro. Dissertação de mestrado. PPGAU-UFPA, 2012.

IBGE - INSTITUTO BRASILEIRO DE GEOGRAFIA E ESTATísTICA. Censo demográfico, 2016. Disponível em: <www.ibge.gov.br> Acesso em: 06/13/2017.

KATO, R.B; BORDALO, B.M; CAMELO, T.S. ANÁLISE DE PERCEPÇÃO QUALITATIVA DO TRANSPORTE PÚBLICO: UM ESTUDO DE CASO NA CIDADE DE BELÉM/PA. REEC

- Revista Eletrônica de Engenharia Civil, Vol. 11 - no 2, 2016.

LEITE, A. D. TRANSPORTE DE PASSAGEIROS POR BARCAS: ANÁLISE ESPACIAL DO SISTEMA DE BILHETAGEM ELETRÔNICA DA REGIÃO METROPOLITANA DO RIO DE JANEIRO. Dissertação de Mestrado apresentada ao Programa de Pós-Graduação em Engenharia de Transportes, COPPE, da Universidade Federal do Rio de Janeiro, 2014

LIMA, J. J; SILVA, R.V; CRUZ, C.C.C.S. Modificações recentes na configuração da periferia de Belém do Pará e suas consequências para mobilidade urbana. III Encontro da Associação Nacional de Pesquisa e Pósgraduação em Arquitetura e Urbanismo, São Paulo, 2014.
RODRIGUES, M. O. Avaliação da qualidade do transporte coletivo da cidade de São Carlos. Dissertação (Mestrado) - Escola de Engenharia de São Carlos, Universidade de São Paulo, 2006.

SMITH, H.; RAEMAEKERS, J. Land use pattern and transport in Curitiba. Land use policy, v. 15, n. 3, p. 233251, July, 1998.

SILVA, M. J. B; DIAS, M. B. URBANIZAÇÃO E QUALIDADE DE VIDA NO DISTRITO DE ICOARACI BELÉM/PARA/BRASIL. Revista Geográfica de América Central Número Especial EGAL - Costa Rica II Semestre 2011 pp. 1-19, 2011.

TOBIAS, M. S. G; NETO, B. C; NEVES, P. B. T. As faces da entropia no transporte urbano na Amazônia: o caso de Belém do Pará - Brasil. Revista dos Transportes Públicos - ANTP - Ano 30/31 - 2008 - 3o e 40 trimestres.

TOBIAS, M. S. G. Transporte hidroviário urbano em Belém: realidade e perspectivas. Revista dos Transportes Públicos - ANTP - Ano 29 - 2007 - 10 trimestre

TIRONI, L. F.; SILVA, L. C. E.; VIANA, L. M.; MEDICI, A. C. Critérios para a geração de indicadores de qualidade e produtividade no serviço público. IPEA - Textos para discursão interna. Brasília, 1991.

VASCONCELLOS, E. D. Transporte urbano nos países em desenvolvimento: Reflexões e propostas. 1a ed. São Paulo: Editoras Unidas, 1996. 